\title{
Radiotherapy of early breast cancer in scleroderma patients: our experience with four cases and a short review of the literature
}

This article was published in the following Dove Press journal:

Breast Cancer:Targets and Therapy

23 January 2012

Number of times this article has been viewed

\author{
George Kyrgias ${ }^{1,2}$ \\ Kiki Theodorou ${ }^{3,4}$ \\ Anna Zygogianni' \\ Konstantinos Tsanadis ${ }^{2}$ \\ Stefanos Zervoudis ${ }^{5}$ \\ John Tzitzikas ${ }^{6}$ \\ Michael Koukourakis ${ }^{7}$ \\ 'Academic Radiotherapy, University \\ of Thessaly, Medical School, Greece; \\ ${ }^{2}$ Radiation Oncology Department, \\ University Hospital of Larissa, \\ Greece; ${ }^{3}$ Academic Medical Physics, \\ University of Thessaly, Medical School, \\ Greece; ${ }^{4}$ Medical Physics Department, \\ University Hospital of Larissa, ${ }^{5} \mathrm{Breast}$ \\ Unit, REA Hospital, Athens, Greece; \\ ${ }^{6}$ Radiation Oncology Department, \\ AHEPA University Hospital of \\ Thessaloniki, Greece; ${ }^{7}$ Radiotherapy- \\ Oncology Department, University \\ Hospital of Alexandroupolis, Greece
}

Correspondence: George Kyrgias University Hospital of Larissa, Radiation Oncology Department, Biopolis, Larissa 4III0, Thessaly, Greece

Tel +302413502050

Fax +302413501013

Email gkyrgias@med.uth.gr
Purpose: Connective vascular diseases (CVD), including scleroderma, are reported to represent for some researchers a relative contraindication and for others absolute contraindication for radiotherapy. The purpose of our study is to add four new cases to the existing body of international literature and to determine whether women with pre-existing scleroderma who have been surgically treated for early breast cancer could undergo postsurgical radiotherapy without serious early and late complications.

Patients and methods: From May 1998 to November 2010, we irradiated for early breast cancer four patients suffering from pre-existing scleroderma; after conservative surgery, we performed whole breast postoperative radiotherapy of 50.4 Gy total dose to the whole breast plus a 9 Gy boost to the tumor bed. We reviewed the records of all four patients and evaluated the early and late reactions using acute radiation morbidity scoring criteria (Radiation Therapy Oncology Group [RTOG], American College of Radiology, Philadelphia, PA) and late radiation morbidity scoring scheme (European Organisation for Research and Treatment of Cancer [EORTC], Brussels, Belgium and RTOG).

Results: After a median follow-up of 105 months (range 12-155 months) the early and late toxicity concerning the skin, the subcutaneous tissues, the lungs, and the heart have been acceptable and are in full accordance with what have been reported in international literature.

Conclusion: This study matches global experience, which shows that patients with scleroderma and breast cancer must be discussed by the multidisciplinary tumor board in order for a personalized treatment strategy to be formulated. Radiation therapy can be proposed as a postsurgical therapeutic option in selected cases.

Keywords: breast radiotherapy, early toxicity, late complications, short review, scleroderma

\section{Introduction}

Adjuvant radiotherapy to the breast is of tremendous value in preventing local failure in women with early-stage breast cancer. Many clinical trials bear this out. They repeatedly show that adjuvant radiotherapy reduces the likelihood of local recurrence and allows for higher rates of breast preservation, and also show how adjuvant breast irradiation should be performed. ${ }^{1-8}$ Many studies in which long-term cosmetic outcome after breast conserving surgery followed by radiotherapy was examined have produced results ranging from good to excellent with most patients. ${ }^{9,10}$

High total dose radiation has been shown to lead to acute or delayed and partly irreversible skin and breast tissue effects (eg, inflammation or pigmentation change, telangiectasias, fat tissue necrosis, breast tenderness). Also, pulmonary and heart complications can be observed. ${ }^{11,12}$ Even morphea, a localized type of scleroderma, can be a 
late complication of breast radiotherapy in non-sclerodermic patients. ${ }^{13-15}$ The long-term effects generally become evident more than 6 months after irradiation.

Moreover, in those rare cases of patients with underlying solitary collagen vascular disease (CVD, eg, scleroderma) or mixed CVD, the treatment may result in considerable fibrosis and retraction of the breast towards the axilla. ${ }^{11}$ It seems indeed that CVD is associated with an increased risk of late radiation-induced normal tissue reaction ${ }^{16}$ and many papers have been published concerning this issue. ${ }^{17-31}$ Some of these included very few cases (one or two) while others reported details of a greater number of subjects but lacked uniformity in terms of both CVD types and cancer sites. ${ }^{18-31}$ The information in these articles is not consistent, with tolerance reported as being anything from good to very poor. ${ }^{17-31}$ Of these studies, the largest one (209 cases/16 with scleroderma) concluded that the decision to perform irradiation on those suffering from scleroderma must be made on a patient-by-patient basis. ${ }^{28}$

\section{Material and methods}

From May 1998 to November 2010, six patients suffering from clinically and laboratory diagnosed scleroderma were operated on for invasive $\mathrm{T}_{1-2} \mathrm{~N}_{0} \mathrm{M}_{0}$ (five cases) or $\mathrm{T}_{\text {is }} \mathrm{N}_{0} \mathrm{M}_{0}$ (in situ - one case) breast cancer. They all underwent conservative surgical excision and were then assessed by the tumor board for adjuvant treatment. Five of them underwent adjuvant chemotherapy whereas hormonal anti-estrogen treatment only was chosen for the patient with the in situ lesion. All patients were candidates for postoperative radiotherapy but two of them were excluded and underwent secondary mastectomy - the first one due to multifocal disease confirmed by the pathological specimen and the second one due to a long history of a predisposition towards skin allergies.

In total, four patients were submitted for postoperative whole breast irradiation with a three-dimensional conformal technique using two opposite tangential $6 \mathrm{MV}$ photonwedged fields plus a supplementary boost to the tumor bed with a single electron-beam field. All four patients provided informed consent.

A CT-based three-dimensional treatment plan was formulated for all patients. The treatment plans were produced using the PLATO ${ }^{\circledR}$ and Oncentra Master Plan ${ }^{\circledR}$ (Nucletron BV, Veenendaal, the Netherlands) treatment planning systems with pencil beam algorithms and with correction for tissue inhomogeneities (Figure 1). All patients received a total dose of 59.4 Gy (50.4 Gy to the whole breast plus a boost of 9 Gy to the tumor bed and the surgical scar) with a conventional fractionation of $1.8 \mathrm{~Gy} /$ day, 5 days per week. We managed to achieve dose homogeneity of $95 \%-105 \%$. According to our quality assurance checks, the correlation between the planned and the delivered doses was well within a $3 \%$ margin.

The quality assurance program of our department includes: (a) full quality control of the linacs with daily dosimetry and verification, (b) quality control of the treatment planning system and verification of the accuracy of the dose calculation using thermoluminescent dosimetry on phantoms, (c) monitor unit calculation for each patient using an independent algorithm for verification purposes, and (d) port films for positioning verification. Finally, in vivo dosimetry studies with TLDs and diodes were performed for the breast irradiation (entrance and exit dose) which showed a good correlation between the doses calculated and the doses actually delivered.

Of the four patients in question, one did not undergo chemotherapy due to in situ cancer. The remaining three each underwent a different chemotherapy regimen, ie,

Patient 1: CMF (cyclophosphamide, methotrexate, fluorouracil) -6 cycles,

Patient 2: CMF-3 cycles + FEC (epirubicin, fluorouracil, cyclophosphamide) -3 cycles,

Patient 3: AC (adriamycin, cyclophosphamide) 4 cycles + TXT (docetaxel) -4 cycles .

We clinically followed up these four patients once a month for the first 2 years, then once every 3 months for the next 3 years and, finally once every 6 months until the submission of this paper.

Using acute radiation morbidity scoring criteria (Radiation Therapy Oncology Group [RTOG], American College of Radiology, Philadelphia, PA) and late radiation morbidity scoring scheme (European Organisation for Research and Treatment of Cancer [EORTC], Brussels, Belgium and RTOG), we evaluated early and late adverse effects on the skin and subcutaneous tissues (clinically), the lung (clinically and by chest CT scans every 3 months for the first 2 years, then after every 6 months) and the heart (clinically, by electrocardiogram [ECG] and by chest CT images).

\section{Results}

Early skin reactions were as follows: grade 1 toxicity - two patients (Figure 2), grade 2 - one patient, and grade 3 - one patient. No grade 4 toxicity was observed and all patients completed the radiotherapy regimen without delays or gaps. No lung or heart toxicity was observed (Table 1).

After a median follow-up of 105 months (ranging from 12 to 155 months) late toxicity of the skin was as follows: grade 0 

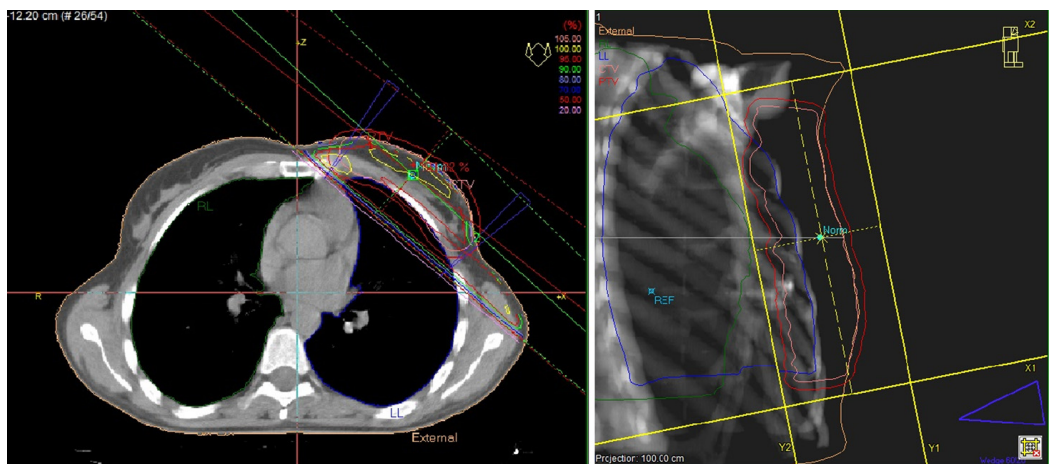

Figure I Treatment planning image of the Patient 4.

toxicity - one patient (after a follow-up of 83 months); grade 1 (slight atrophy) - two patients (after a follow-up of 12 and 127 months); grade 2 - in one patient (after a follow-up of 155 months). There was no grade 3 or 4 toxicity. Regarding subcutaneous tissue toxicity, we had two patients with grade 1 , one patient with grade 2 , and one patient with grade 0 -toxicity. Only one patient developed grade 1 lung toxicity. Minor increase in the lung density within the radiation portals was noted in one out of four patients at CT-scan evaluation. No case presented with clinical respiratory symptomatology. None of the patients developed heart toxicity (Table 2).

No breast pain either acute or chronic has been reported and all four patients were recorded as alive and without locoregional relapse or progression of disease at the time of the study (November 2011).

\section{Discussion}

The current approach to the treatment of early breast cancer is to administer conservative surgery (ie, lumpectomy, quadrantectomy, or partial mastectomy) plus postoperative adjuvant irradiation and, when indicated, adjuvant chemotherapy. This approach is preferable for esthetic reasons, particularly with younger patients and is therapeutically as effective as older more invasive surgical treatments.

On the other hand, CVDs, including scleroderma, are reported to represent for some researchers a relative contraindication and for others an absolute contraindication for radiotherapy. ${ }^{16}$ Therefore, in young people with early breast cancer and a history of scleroderma, the therapeutic decision (conservative excision plus radiotherapy versus total mastectomy) is something which needs serious consideration.

In the past, it has been shown that patients with CVD present increased radiation sensitivity. ${ }^{26,30,31}$ Some authors proposed decreasing the doses of radiotherapy in order to improve tolerance. ${ }^{28}$ However, their articles suffer from a lack of homogeneity in terms of both cancers ${ }^{18-31}$ and types of $\mathrm{CVD}^{18,22,23,29,35}$ that makes it difficult to draw a solid conclusion in a specific setting.
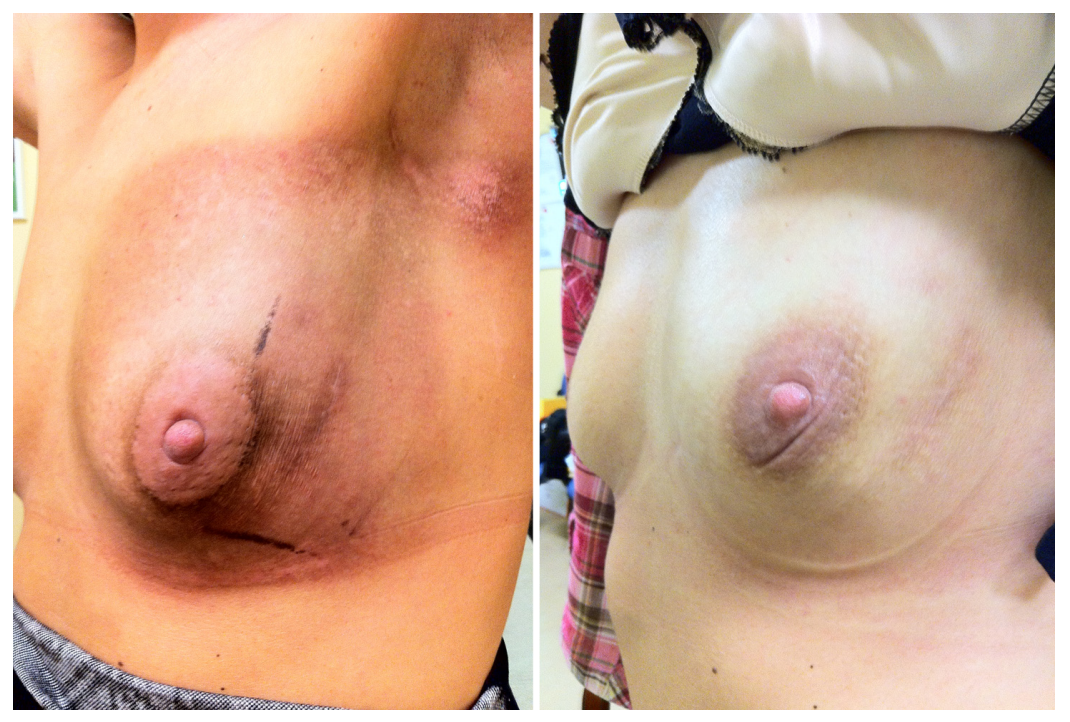

Figure 2 Early toxicity in our scleroderma Patient 4. Left: grade I skin reaction at the end of the breast irradiation. Right: complete healing 6 months later. 
Table I Grade of early toxicity after breast radiotherapy in our scleroderma suffering patients

\begin{tabular}{lllll}
\hline Patient & Skin & Lung & Heart & Breast pain \\
\hline 1 & 2 & 0 & 0 & NR \\
2 & 1 & 0 & 0 & NR \\
3 & 3 & 0 & 0 & NR \\
4 & 1 & 0 & 0 & NR
\end{tabular}

Abbreviation: NR, not reported.

Morris and Powel ${ }^{28}$ looked at 209 patients with CVD (collagen vascular disease), 16 of whom presented with scleroderma. The authors concluded that radiation therapy was feasible, though the higher risk of early and late reactions must always be taken into account. They emphasized the importance of adapting the treatment protocol to each patient. The drawback of their results is that they referred to the whole population of CVD patients, which makes it difficult to know the treatment tolerance in those suffering from scleroderma. ${ }^{28}$

Lin et al ${ }^{29}$ published a study which focused on 86 courses of RT for 73 patients with CVD, nine of them suffering from scleroderma. The researchers concluded that the treatment is generally well tolerated. However, when RT is administered to patients suffering from CVD, there seems to be a greater possibility of late toxicity. RT administered to the pelvis or administered when systemic lupis erythematosus or scleroderma is present may involve an even higher level of risk as far as severe toxicity is concerned. Such issues should be taken into account when RT is being considered as a treatment option for these patients.

Ross et $\mathrm{al}^{23}$ reported a series of 61 patients with CVD (including three with scleroderma) treated for different types of tumors with a follow-up of 18 months. Sixty percent of the patients received doses higher than $40 \mathrm{~Gy}$. They concluded that there were more early and late reactions.

Chen et $\mathrm{a}^{18}$ reported a series of 36 patients (four with scleroderma), with a median follow-up of 12.5 years. The results for the 36 patients compared with a control group were as follows: early reactions: $14 \%$ vs $8 \%$, respectively and a significantly higher rate of late reactions ( $17 \%$ vs $3 \%$, respectively) but as the study involved such a small number of cases, no statistical significance can be attached to the results.

Finally, a very interesting study by Gold et al from Mayo Clinic (Rochester, NY) suggests that the number of organ systems involved in CVD may have some predictive value for late complications of breast radiotherapy in these patients (ie, the greater the number of systems involved, the higher the likelihood of late complications may be). ${ }^{32}$

Accelerated partial breast irradiation (APBI) with either breast brachytherapy or intraoperative radiotherapy (IORT) could be a good option for women with a history of CVD who are suffering from early-stage breast cancer. Most studies have concluded that, although the results need to be confirmed, APBI appears to be equally as safe and well tolerated as external-beam radiotherapy (EBRT).

However, there is still much skepticism about this issue because of concerns regarding increased toxicity. As a result, patients suffering from CVD are generally excluded from most clinical trials studying breast APBI (eg, the NSABP B-39/RTOG-0413 study). ${ }^{33}$

The percentage of women with persistent post-treatment breast pain amounts to $25 \%-60 \%$ depending on the treatment modalities. ${ }^{34}$ Breast pain is reported even in non-irradiated women undergoing conservative breast cancer treatment, but it is also evident that radiotherapy significantly increases the likelihood of this side effect, which in some cases can be long lasting; in fact, the literature refers to breast pain as a possible side effect of breast-only irradiation at different rates of $8.7 \%-23.1 \%{ }^{35}$ and up to $58 \% .^{36}$

This side effect possibly reflects a complex pathophysiology involving touching and pressure on the treated breast, ${ }^{37}$ preoperative, intraoperative, and post-operative risk factors, ${ }^{34}$ and even the age of the patient (mainly up to 39 years). ${ }^{35}$ Moreover, it seems that chemotherapy increases the possibility of post-irradiation breast pain. ${ }^{35,36}$

Finally, in the study by Matthews et al, ${ }^{38}$ the paininsomnia-fatigue cluster of symptoms was associated with some individual characteristics such as optimism, selfesteem, and positive and negative mood.

Table 2 Grade of late toxicity after breast radiotherapy in our scleroderma suffering patients

\begin{tabular}{lllllll}
\hline Patient & $\begin{array}{l}\text { Follow-up } \\
\text { (months) }\end{array}$ & Skin & $\begin{array}{l}\text { Subcutaneous } \\
\text { tissue }\end{array}$ & Lung & $\begin{array}{l}\text { Heart } \\
\text { preast }\end{array}$ \\
\hline 1 & 155 & 2 & 1 & 0 & 0 & NR \\
2 & 127 & 1 & 1 & 1 & 0 & NR \\
3 & 83 & 0 & 2 & 0 & 0 & NR \\
4 & 12 & 1 & 0 & 0 & 0 & NR \\
\hline
\end{tabular}

Abbreviation: NR, not reported. 
The lack of breast pain in our patients is possibly due to the low fractionation scheme (1.8 Gy). On the other hand, our patients' age at the time of radiotherapy ranged from 39 to 62 years and our Patient 4 (aged 39 years) did not receive any chemotherapy.

\section{Conclusion}

Our small-scale study shows that certain patients with scleroderma may undergo breast radiotherapy for breast cancer without significant side effects, but there is insufficient evidence for us to draw more conclusions safely.

Given the small number of patients with scleroderma who require radiotherapy for breast cancer, only multicenter prospective randomized studies can provide enough results for definite conclusions to be drawn. Until such results are available, the therapeutic proposal must be decided upon in each case by a multidisciplinary tumor board. In reaching its decision, the board must achieve a balance of therapeutic gain, toxicity expectation, and cosmetic results and last, but not least, the wishes of the patient herself, who must provide informed consent.

After discussion by the multidisciplinary tumor board in order for a personalized treatment strategy to be formulated, radiation therapy could be proposed as a postsurgical therapeutic option on condition that:

1. there is no systemic scleroderma and the patient's skin is not especially sensitive to sunlight (risk of photodermatitis),

2. the anatomy of the patient's breast and chest permits state of the art radiotherapy treatment planning to maximize the protection of the underlying organs at risk (OARs), ie, lung and heart,

3. an optimal radiotherapy technique adapted to the patient's anatomy can be applied, ${ }^{30}$

4. a thorough follow-up of the patient day-by-day during the course of the treatment is practicable,

5. the patient is fully capable of taking responsibility to care for her skin and to report any symptom that could be related to the breast irradiation.

Since all but one of our patients (ie, the patient with the in situ cancer) underwent a different chemotherapy regimen, the impact of the chemotherapy in the development of acute and late toxicity cannot be appraised.

Given that a small number of publications report scleroderma-like changes by the use of docetaxel or paclitaxel, ${ }^{39-44}$ chemotherapy of any regimen should ideally be avoided in patients with CVD until more data from prospective randomized studies are available, as a review publication from
Harvard suggests. ${ }^{45}$ Nonetheless, if chemotherapy is essential, no drugs which can cause radiation recall phenomenon must be prescribed (eg, anthracyclines, mitoxantrone, etc).

Last but not least, the challenge to identify the patients with scleroderma who are at greatest risk for radiation-related toxic effects will be continuous, as a very important clinical investigation for Mayo Clinic concluded. ${ }^{46}$

\section{Acknowledgment}

The authors received no funding for this work.

\section{Disclosure}

The authors report no conflicts of interest in this work.

\section{References}

1. Fisher B, Anderson S, Bryant J, et al. Twenty-year follow-up of a randomized trial comparing total mastectomy, lumpectomy and lumpectomy plus irradiation for the treatment of invasive breast cancer. $N E n g l$ J Med. 2002;347(16):1233-1241.

2. Clark RM, Mc Culloch PB, Levine MN, et al. Randomized clinical trial to assess the effectiveness of breast irradiation following lumpectomy and axillary dissection for node-negative breast cancer. J Natl Cancer Inst. 1992;84(9):683-689.

3. van Dongen JA, Voogd AC, Fentiman IS, et al. Long-term results of a randomized trial comparing breast-conserving therapy with mastectomy: European Organization for Research and Treatment of Cancer 10801 trial. J Natl Cancer Inst. 2000;92(14):1143-1150.

4. Veronesi U, Cascinelli N, Mariani L, et al. Twenty-year follow-up of a randomized study comparing breast-conserving surgery with radical mastectomy for early breast cancer. $N$ Engl J Med. 2002;347(16): 1227-1232.

5. Jacobson JA, Danforth DN, Cowan KH, et al. Ten-year results of a comparison of conservation with mastectomy in the treatment of stage I and II breast cancer. N Engl J Med. 1995;332(14):907-911.

6. Blichert-Toft M, Rose C, Andersen JA, et al. Danish randomized trial comparing breast conservation therapy with mastectomy: six years of life-table analysis. Danish Breast Cancer Cooperative Group. J Natl Cancer Inst Monogr. 1992;11:19-25.

7. Arriagada R, Lê MG, Guinebretière JM, Dunant A, Rochard F, Tursz T. Late local recurrences in a randomised trial comparing conservative treatment with total mastectomy in early breast cancer patients. Ann Oncol. 2003;14(11):1617-1622.

8. Clarke M, Collins R, Darby S, et al. Effects of radiotherapy and of differences in the extent of surgery for early breast cancer on local recurrence and 15-year survival: an overview of the randomized trials. Lancet. 2005;366(9503):2087-2106.

9. Toledano A, Garaud P, Serin D, et al. Concurrent administration of adjuvant chemotherapy and radiotherapy after breast-conserving surgery enhances late toxicities: long-term results of the ARCOSEIN multicenter randomized study. Int J Radiat Oncol Biol Phys. 2006;65:324-332.

10. Vrieling C, Collette L, Fourquet A, et al. The influence of patient, tumor and treatment factors on the cosmetic results after breast-conserving therapy in the EORTC 'boost vs no boost' trial. EORTC Radiotherapy and Breast Cancer Cooperative Groups. Radiother Oncol. 2000;55(3): 219-232.

11. Sassi ML, Jukkola A, Riekki R, et al. Type I collagen turnover and cross-linking are increased in irradiated skin of breast cancer patients. Radiother Oncol. 2001;58(3):317-323.

12. Trombetta M, Valakh V, Julian TB, Werts ED, Parda D. Mammary fat necrosis following radiotherapy in the conservative management of localized breast cancer: does it matter? Radiother Oncol. 2010;97(1):92-94. 
13. Mosterd K, Winnepenninckx V, Vermeulen A, van Neer PA, van Neer FJ, Frank J. Morphea following surgery and radiotherapy: an evolving problem. J Eur Acad Dermatol Venereol. 2009;23(9):1099-1101.

14. Herrmann T, Günther C, Csere P. Localized morphea - a rare but significant secondary complication following breast cancer radiotherapy. Case report and review of the literature on radiation reaction among patients with scleroderma/morphea. Strahlenther Onkol. 2009;185(9): 603-607.

15. Akay BN, Sanli H, Heper AO. Postirradiation linear morphoea. Clin Exp Dermatol. 2010;35(4):e106-e108.

16. Hölscher T, Bentzen SM, Baumann M. Influence of connective tissue diseases on the expression of radiation side effects: a systematic review. Radiother Oncol. 2006;78(2):123-130.

17. Darras-Joly C, Wechsler B, Blétry O, Piette JC. De novo systemic sclerosis after radiotherapy: a report of 3 cases. J Rheumatol. 1999;26: 2265-2267.

18. Chen AM, Obedian E, Haffty BG. Breast-conserving therapy in the setting of collagen vascular disease. Cancer J. 2001;7(6):480-491.

19. Tournillac I, Dandurand M, Guillot B. Bullous lichen sclerosus after radiotherapy. Ann Dermatol Venereol. 1998;125(2):121-123. French.

20. Mayr NA, Riggs CE Jr, Saag KG, Wen BC, Pennington EC, Hussey DH. Mixed connective tissue disease and radiation toxicity. A case report. Cancer. 1997;79(3):612-618.

21. Phan C, Mindrum M, Silverman C, Paris K, Spanos W. Matched-control retrospective study of the acute and late complications in patients with collagen vascular diseases treated with radiation therapy. Cancer J. 2003;9(6):461-466.

22. Haustein UF. Exacerbation of progressive scleroderma following roentgen therapy. Hautarzt. 1990;41(8):448-450. German.

23. Ross JG, Hussey DH, Mayr NA, Davis CS. Acute and late reactions to radiation therapy in patients with collagen vascular diseases. Cancer. 1993;71(11):3744-3752.

24. De Naeyer B, De Meerleer G, Braems S, Vakaet L, Huys J. Collagen vascular diseases and radiation therapy: a critical review. Int J Radiation Oncology Biol Phys. 1999;44(5):975-980.

25. Fleck R, McNeese MD, Ellerbroek NA, Hunter TA, Holmes FA. Consequences of breast irradiation in patients with pre-existing collagen vascular diseases. Int J Radiat Oncol Biol Phys. 1989;17(4):829-833.

26. Delanian S, Maulard-Durdux C, Lefaix JL, Housset M. Major interactions between radiation therapy and systemic sclerosis: is there an optimal treatment? Eur J Cancer. 1996;32A(4):738-739.

27. Wenzel J. Scleroderma and malignancy. Mechanisms of interrelationship. Eur J Dermatol. 2002;12(3):296-300.

28. Morris MM, Powel SN. Irradiation in the setting of collagen vascular disease: acute and late complications. J Clin Oncol. 1997;15(7): $2728-2735$

29. Lin A, Abu-Isa E, Griffith KA, Ben-Josef E. Toxicity of radiotherapy in patients with collagen vascular disease. Cancer. 2008;113(3): 648-653.

30. Ransom DT, Cameron FG. Scleroderma - a possible contra-indication to lumpectomy and radiotherapy in breast carcinoma. Australas Radiol. 1987;31(3):317-318.
31. Cooper SG, Denham JW. Progressive systemic sclerosis (diffuse scleroderma) and radiotherapy. Br J Radio. 1990;63(754):804-805.

32. Gold DG, Miller RC, Pinn ME, Osborn TG, Petersen IA, Brown PD. Chronic toxicity risk after radiotherapy for patients with systemic sclerosis (systemic scleroderma) or systemic lupus erythematosus: association with connective tissue disorder severity. Radiother Oncol. 2008;87(1):127-131.

33. Dragun AE, Harper JL, Olyejar SE, Zunzunegui RG, Wazer DE. The use of adjuvant high-dose rate brachytherapy in patients with collagen vascular disease: a collaborative experience. Brachytherapy. 2011; 10(2):121-127.

34. Andersen KG, Kehlet H. Persistent pain after breast cancer treatment: a critical review of risk factors and strategies for prevention. J Pain. 2011;12(7):725-746.

35. Lundstedt D, Gustafsson M, Steineck G, et al. Risk factors of developing long-lasting breast pain after breast cancer radiotherapy. Int $J$ Radiation Oncol Biol Phys. 2011. [Epub ahead of print.] doi:10.1016/j. ijrobp.2011.05.065.

36. Gärtner R, Jensen MB, Nielsen J, Ewertz M, Kroman N, Kehlet H. Prevalence of and factors associated with persistent pain following breast cancer surgery. JAMA. 2009;302(18):1985-1992.

37. Lundstedt D, Gustafsson M, Malmström P, et al. Symptoms 10-17 years after breast cancer radiotherapy data from the randomised SWEBCG91-RT trial. Radiother Oncol. 2010;97(2):281-287.

38. Matthews EE, Schmiege SJ, Cook PF, Sousa KH. Breast cancer and symptom clusters during radiotherapy. Cancer Nurs. 2011. [Epub ahead of print.] doi:10.1097/NCC.0b013e3182277222.

39. Cleveland MG, Ajaikumar BS, Reganti R. Cutaneous fibrosis induced by docetaxel: a case report. Cancer. 2000;88(5):1078-1081.

40. Battafarano DF, Zimmerman GC, Older SA, Keeling JH, Burris HA. Docetaxel (Taxotere) associated scleroderma-like changes of the lower extremities. A report of three cases. Cancer. 1995;76(1):110-115.

41. Hassett G, Harnett P, Manolios N. Scleroderma in association with the use of docetaxel (taxotere) for breast cancer. Clin Exp Rheumatol. 2001;19(2):197-200.

42. Kupfer I, Balguerie X, Courville P, Chinet P, Joly P. Sclerodermalike cutaneous lesions induced by paclitaxel: a case study. J Am Acad Dermatol. 2003;48(2):279-281.

43. Läuchli S, Trüeb RM, Fehr M, Hafner J. Scleroderma-like drug reaction to paclitaxel (Taxol). Br J Dermatol. 2002;147(3):619-621.

44. De Angelis R, Bugatti L, Cerioni A, Del Medico P, Filosa G. Diffuse scleroderma occurring after the use of paclitaxel for ovarian cancer. Clin Rheumatol. 2003;22(1):49-52.

45. Wo J, Taghian A. Radiotherapy in setting of collagen vascular disease. Int J Radiat Oncol Biol Phys. 2007;69(5):1347-1353.

46. Gold DG, Miller RC, Petersen IA, Osborn TG. Radiotherapy for malignancy in patients with scleroderma: The Mayo Clinic experience. Int $J$ Radiat Oncol Biol Phys. 2007;67(2):559-567.
Breast Cancer: Targets and Therapy

\section{Publish your work in this journal}

Breast Cancer: Targets and Therapy is an international, peerreviewed open access journal focusing on breast cancer research, identification of therapeutic targets and the optimal use of preventative and integrated treatment interventions to achieve improved outcomes, enhanced survival and quality of life for the cancer patient.

\section{Dovepress}

View the full aims and scopes of this journal here. The manuscrip management system is completely online and includes a very quick and fair peer-review system, which is all easy to use. Visit http:// www.dovepress.com/testimonials.php to read real quotes from published authors. 